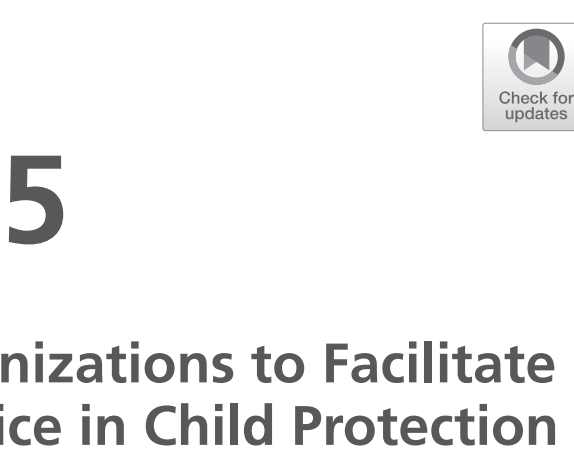

\title{
Re-designing Organizations to Facilitate Rights-Based Practice in Child Protection
}

\section{Eileen Munro and Andrew Turnell}

\section{Introduction}

The actions of individual child protection workers are the final steps in how an organization promotes the realization of children's rights, with those actions being radically shaped in helpful and unhelpful ways by the organizational context. In many jurisdictions, managerialism has so constrained individual discretion and choice of action that rights-based practice is hard to achieve. Recent reforms in England aim to increase professional autonomy and decrease the top-down control mechanisms of managerialism such as proceduralization and key performance indicators that measure professional activity rather than outcomes for children. This chapter takes the example of implementing the Signs of Safety

\section{E. Munro ( $₫)$}

London School of Economics, London, UK e-mail: e.munro@lse.ac.uk

A. Turnell

Resolutions Consultancy, East Perth, WA, Australia e-mail: andrew.turnell@resolutionsconsultancy.com 
practice framework in ten local authorities in England to illustrate how whole system reform is needed to support workers in achieving rightsbased practice.

In England, widespread dissatisfaction with previous efforts to reform the child protection system led to the government establishing the Munro Review of Child Protection (2011). The review's analysis of the system of child protection identified how efforts to improve practice by providing greater guidance had combined with a blame culture and the introduction of managerialism's framework of procedures and key performance indicators to lead, over time, to a system focused on compliance with process, not on the impact on children and their families. Efforts to help professionals make sound judgments had slowly expanded guidance to the extent that judgment was increasingly replaced by rule-following, radically diminishing the professional role and leading to serious recruitment and retention problems. The system was so prescriptive that it could not readily adapt to the specific needs of individual children; practice was monitored by checking compliance with procedures, and not by seeing whether children had benefited from the service; keeping records up to date became more important than forming relationships with parents and children. One study reported that workers were spending up to $80 \%$ of their time in front of computers (White et al. 2010), and risk management was distorted by defensive practice where professionals sought to protect themselves from blame by sticking rigidly to procedures even when this led to choices that they did not consider were best for children. This is referred to as 'weak discretion', where autonomy is limited and decision-making in practice is predominantly routinized and controlled (see Skivenes and Sørsdal 2018: Chap. 4 in this book). Crucially such a system of rules fails to provide the 'requisite variety' (Ashby 1991) to meet the needs of individual children; skilled professionals are needed to use their judgment in applying general knowledge to the specific circumstances of a child.

While Signs of Safety is by no means the only practice framework that upholds and facilitates the rights of the child, the implementation of Signs of Safety is offered here as illustrative of the range of issues that 
shifting to a more rights-based approach raises (Turnell 2012). The work in England has highlighted the extent to which the organizational system can, possibly inadvertently, create obstacles to professionals' efforts to uphold, facilitate and ultimately respect children's rights.

Rights can be divided into three groups: provision, participation and protection rights. The focus here is mainly on the first two sets of rights since they had been more neglected in the former way of working in which risk management was central.

\section{$2 \quad$ Provision Rights and Promoting Development}

When family care poses a threat to children's healthy development, workers need to balance the dangers against the benefits that their intervention offers the child. In practice, there is considerable evidence that this is difficult to achieve. History in many jurisdictions reveals a fluctuating pattern of giving priority to child rescue or to family preservation (Parton 2009; Gilbert et al. 2011; Featherstone et al. 2013). Yet both dimensions are equally necessary when deciding what is in the best interests of children. Leaving children in potentially dangerous circumstances has obvious implications for whether a child realizes their survival and development rights, but so does removing them. Children who are removed lose intimate contact with their birth parents (and sometimes lose all contact). They also face the risk of their developmental needs not being adequately met—research on the outcomes for children raised in alternative care reveals how this is not a simple solution (Thoburn 2017).

A balanced assessment depends, in part, on having a practice approach that offers guidance on how to achieve the best possible balance between the benefits of interventions with non-intervention. In Signs of Safety, a balanced analysis is central to assessment (Table 5.1). 
Table 5.1 Signs of safety assessment and planning framework

Signs of Safety Assessment and Planning Framework: Seven Analysis Categories (Professional Language)

\begin{tabular}{|c|c|c|}
\hline $\begin{array}{c}\text { What are we worried } \\
\text { about? }\end{array}$ & What's working well? & What needs to happen? \\
\hline $\begin{array}{l}\text { HARM: Past hurt, injury or abuse } \\
\text { to the child (likely) caused by } \\
\text { adults. Also includes risk taking } \\
\text { behaviour by children/teens that } \\
\text { indicates harm and/or is harmful } \\
\text { to them. }\end{array}$ & $\begin{array}{l}\text { EXISTING STRENGTHS: People, } \\
\text { plans and actions that contribute } \\
\text { to a child's wellbeing and plans } \\
\text { about how a child will be made } \\
\text { safe when danger is present. }\end{array}$ & $\begin{array}{l}\text { SAFETY GOALS: The behaviours } \\
\text { and actions the child protection } \\
\text { agency needs to see to be satisfied } \\
\text { the child will be safe enough to } \\
\text { close the case. }\end{array}$ \\
\hline $\begin{array}{l}\text { DANGER STATEMENTS: The harm } \\
\text { or hurt that is believed likely to } \\
\text { happen to the child(ren) if nothing } \\
\text { in the family's situation changes. }\end{array}$ & $\begin{array}{l}\text { EXISTING SAFETY: Actions taken } \\
\text { by parents, caring adults and } \\
\text { children to make sure the child is } \\
\text { safe when the danger is present. }\end{array}$ & $\begin{array}{l}\text { NEXT STEPS: The immediate next } \\
\text { actions that will be taken to build } \\
\text { future safety. }\end{array}$ \\
\hline $\begin{array}{l}\text { Complicating Factors: Actions and } \\
\text { behaviors in and around the } \\
\text { family and child and by } \\
\text { professionals that make it more } \\
\text { difficult to solve danger of } \\
\text { future abuse. }\end{array}$ & & \\
\hline
\end{tabular}

In a meeting between the social worker and family (sometimes with other professionals also present), the three columns are completed. After completion, both professionals and family members present are asked individually to answer a scaling question from zero to ten of how much danger they think there is. Conflicting scores lead to discussions of why people disagree or what would make them give a higher score.

Achieving a balanced assessment, however, requires significant organizational support based on a realistic understanding of how difficult the task is and giving greater weight to the importance of professional judgment and use of discretion in assessing a family. In England, the organizational obstacles we encountered were a mix of practical and cultural. One obstacle was relatively easy to deal with: revising guidance and forms to capture the principles, terminology and methods of the practice framework. Integrating the guidance into the IT system was more problematic in part because of the expense. The most difficult obstacles were cultural. 
The key culture challenges were lessening the process-driven blame culture and changing priorities so workers had more time with families and more time for critical reflection (Munro et al. 2016).

A defensive blame culture was widespread. This can lead the individual worker (at whatever level of seniority) to place more weight on the option that offers minimum risk of blame to themselves or their agency than on the option that their professional assessment concludes is in the best interests of the child. In England, the influence of 'covering one's back' is vividly illustrated by the rise in applications for care orders to remove children whenever there is a high-profile death of a child from maltreatment (see, for example, Elsley 2010). Defensive practice was also apparent in the tendency to interpret guidance as fixed rules rather than as principles to inform professional judgment, which was their original purpose.

An alternative to a defensive culture is a just culture. Here, a just culture implies that professional case-workers can be confident that their work will always be judged according to reasonable standards even if a tragedy occurs. Hence, the focus of their decision-making can be on the protection of the child and not themselves or their agency. The two challenges to achieving this are agreeing on 'reasonable standards' and changing the culture.

On the first, there is a considerable literature from other high-risk areas of work to help in the effort to reduce defensive practices, for example in medicine (Department of Health 2001; Dekker 2007) and in policing (College of Policing 2009). The latter publication contains 'risk principles' which were produced by the College of Policing to tackle the problem of reducing defensive practice. These were used as a starting point for discussion within child protection of how to define reasonable standards and subsequently produce a version specific to this area of work.

Agreeing on reasonable standards is not sufficient. Senior managers need to show they endorse them and give a clear message that they will back their workforce if practice meets these criteria. In addition, all need to understand how powerfully and automatically hindsight distorts our 
judgment of past behaviour (Fischhoff 1975). Once we know what happened, it looks so obvious that this was the likely causal pathway that would ensue. In contrast, those involved at the time would have seen several plausible pathways down which events might unfold.

A just culture was also encouraged by reforming the quality assurance system. In the past, this had focused on checking whether records showed evidence of compliance with statutory requirements and tended to be experienced as punitive and anxiety-provoking by workers. The new quality-assurance system aims to be a collaborative learning process that seeks to understand not just what the worker did but why he or she took those actions, how he or she reasoned to reach that conclusion and what organizational factors influenced the process, providing managers with feedback on the realities of the practice environment. Only then is a judgment formed about the quality of the worker's practice.

Another necessary organizational change involved giving greater importance to critical reflection, supervision and group support. In short, encouraging what Kahneman (2011) describes as 'slow' thinking to review the 'fast' thinking that figures in so much direct work. While supervision is generally recognized as important, in practice it had become undervalued and often focused on checking compliance with case processing rather than being a forum for reviewing one's reasoning about a case (Rushton and Nathan 1996; O’Donoghue and Tsui 2013).

This chapter mainly talks about the child protection organizational system but this system is of course a subsystem of others. In England, they are part of a local authority and of the national political system. These wider systems are also major influences on what happens to children. Fundamental to all reforms is sufficient funding to be able to provide a high-quality service to children, undertaking the skilled work with families of assessing their strengths and dangers, helping the family to reduce the danger to children or providing good-quality alternative care when this cannot be achieved in a timespan that meets the child's needs. The GC on Article 19 (Unicef 2011) makes it clear that states parties have a duty to support families but the level of funding provided is influenced by political and economic factors. At present in England, as in many developed countries, the economic policy of austerity is a major complicating factor. 


\section{Respecting Participation Rights}

Participation has been conceptualized as on a continuum and needs to take account of the evolving capacities of the child (Lansdown 2000), and this right is essential in a rights-based approach (see both Pösö 2018 and Sandberg 2018: Chaps. 6 and 2 in this book). Studies of child protection practice, however, have persistently reported failings in adequately respecting this right (Thomas 2015; Ferguson 2017). By practising Signs of Safety, the right to participation features in each step of the process, and with a focus not just on how this contributes to protecting the child, but also on how the whole experience of being involved in the child protection system can be managed in a way that minimizes distress and harm to the child.

\subsection{Listening to Children}

Children are clearly a major source of information about what is happening to them, how they are experiencing it and what they wish would happen. Even pre-verbal or disabled children can communicate their feelings. Their right to be heard is captured in Article 12 of the CRC. Social workers in England have been frequently criticized for not spending enough time with children and listening to their views (Research in Practice 2015). The Children's Rights Director for England sought feedback from fifty children about their experience of coming into care and found that more than half the children had not known they were coming into care until it actually happened and were not prepared for this radical change in their lives: 'Someone could have explained things so I could understand what was happening' (Morgan 2007).

The failure to spend time with children is often blamed on individual workers, with people ascribing it to deficiencies in practitioner skill or motivation. However, in the implementation of Signs of Safety, listening to children was an area where change was welcomed and very rapidly achieved, suggesting that organizational factors have played a stronger role than individual ones in omitting children from the 
conversation. Staff were enthusiastic in using My Three Houses ${ }^{1}$ or similar methods to shape the conversation, but organizational changes were also important.

The My Three Houses tool can be used at any stage in a child's progress through child protection services and helps workers gain an understanding of the child's lived experience and their hopes and fears. A worker can simply use paper with pencils and crayons or use the My Three Houses app on their tablet (http://resolutionsconsultancy.com/app-support). The 'three houses' are the House of Worries, the House of Good Things (the present) and the House of Wishes (the future). Below is a worked example (anonymized) to illustrate the richness of the information gathered (Picture 5.1).

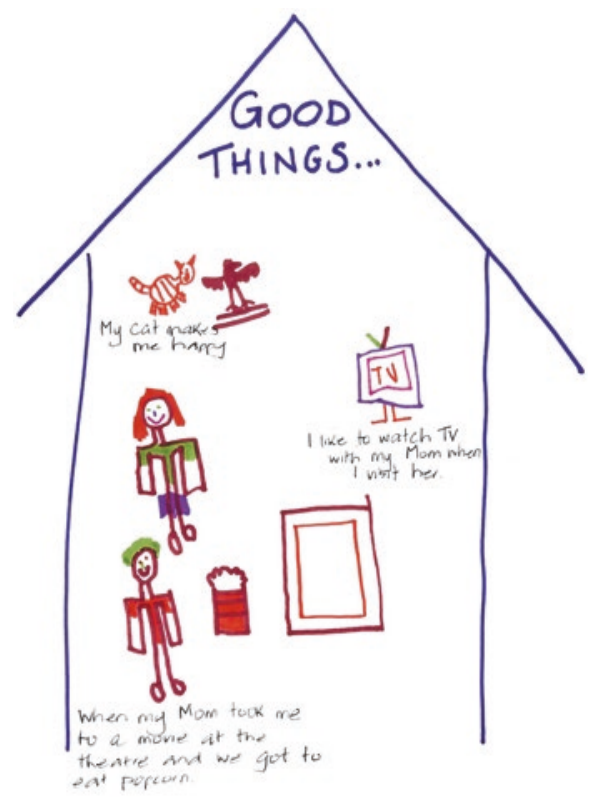

Picture 5.1 My three houses-photos in a series 


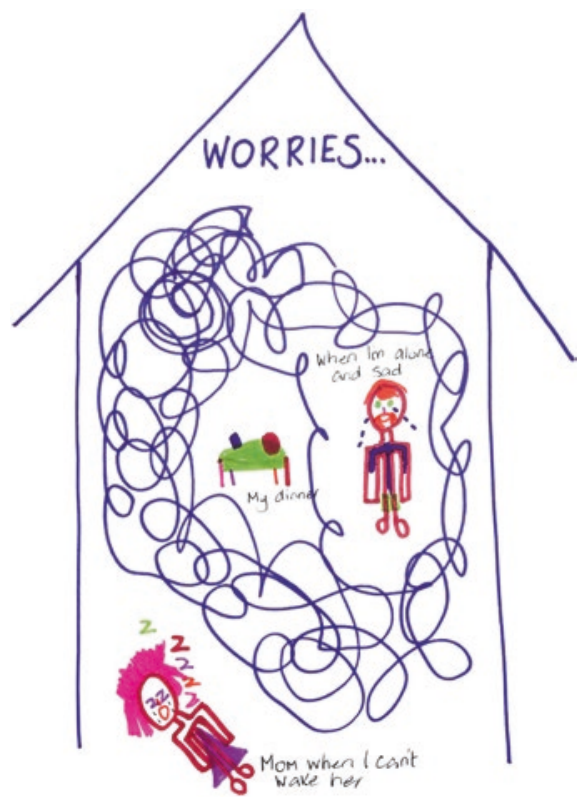

Picture 5.1 (continued)

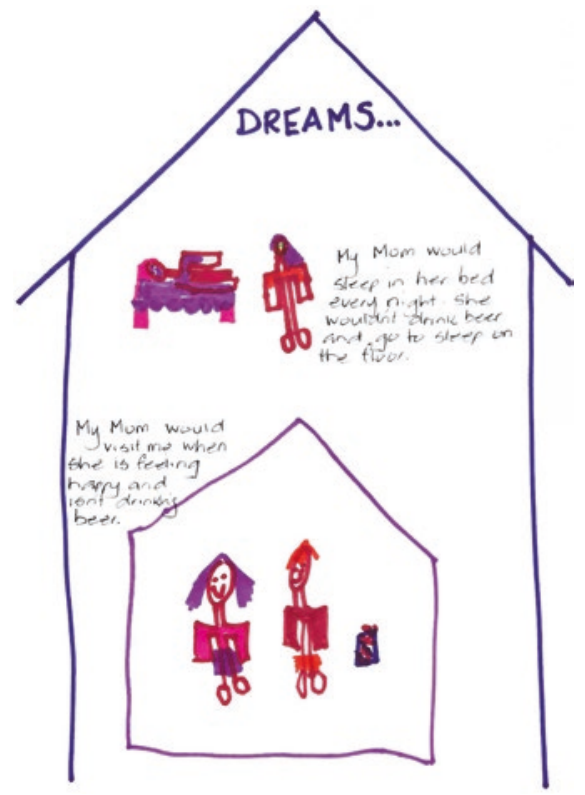

Picture 5.1 (continued) 
Providing training and tools were not the most significant factors in achieving change: senior managers also changed their messages and actions. Besides saying that children needed to be listened to (a sentiment to which they would always have at least paid lip-service), they reinforced this message by asking to see and hear about children's views, expecting children's views to be available for case discussions, looking for them when auditing a case and praising workers for good practice.

Practical changes were also needed. A major problem was altering the IT software so that children's views, in whatever format, could be uploaded to be central to the case file. An interim solution was to attach them as an appendix but this risks their being overlooked or being seen as less important. The My Three Houses app that was developed required workers to have tablets with them when visiting children. Wherever possible interviews with children should be conducted where the child feels comfortable and familiar such as the child's home or the school, but if there is a need to conduct them in the agency offices then suitable room space is needed.

\subsection{Involving Children in Creating and Implementing a Safety Plan}

It might seem straightforward that listening to children more would lead to their information and opinions being used more in case planning, but we found that this was not always the case. The ongoing and pervading influence of the compliance culture showed its impact with some practitioners treating the task of listening to children as a discrete box to be ticked. When this happened, adult views and voices still tended to dominate case discussions and planning, and the child's rights were effectively set aside. To address this problem, it was important to train workers, supervisors and managers in how to integrate and use children's views within the entire trajectory of the case work and how to continue to involve children on an ongoing basis. Most critically, managers and supervisors need to lead for this broader involvement of the child and their views because creating the space where 
children genuinely contribute and participate is always challenging. The involvement of children is gradually improving as workers, supervisors and managers see more examples of good practice and understand the process changes required to facilitate children's participation. There are indications that the overall culture of the agency is becoming more sharply focused on children (Munro et al. 2016).

Planning how to keep children safe is a key task in children's services work. In Signs of Safety practice, this is done by formulating 'safety plans' with the family and, where appropriate, other professionals. Involving children in safety plans raises many issues, including how to manage different priorities and sensibilities between children and professionals about what is in the child's best interests. Respectful engagement with children means that their views should be taken seriously and considered though not necessarily acted upon - an issue for which there is no rulebased solution but requires case-by-case deliberation.

It was found that, in many instances, adults' reasons for overriding children's views stemmed from defensive practice. For example, in one case, Matilda, a 13-year-old girl living with her father, was only allowed contact with her mother in the community, not in the mother's home because of concerns that she would be exposed to violence and drugtaking there. Matilda kept going missing overnight but neither she nor her mother would admit she was staying there. Matilda made it clear that she was worried about her mother's well-being and wanted to visit her mother at home. The social worker decided to change the safety plan and seek to allow Matilda to visit her mother safely and Matilda then came up with her own safety plan.

'Mum and dad to arrange when I can go and see mum, this needs to happen quickly.'

'I want the flat to be clean and tidy, if it is not I want mum to take me out for dinner.'

'Mum to make sure she is not drinking any alcohol or take drugs while I am there'. 
'Mum will agree that I will call dad if she has been drinking, if dad is not there I call will call mum's sister, if she is not there then I will call my Nan and someone will pick me up.'

I do not want Jason to be there when I am seeing mum, if he comes then mum has to tell him to leave or i will go home.' 'If Jason is angry then mum will call the police, if this does not happen then I will not go to mum's house again.'

'Me and mum communicate with Dad and tell him when I get there and when I will be home.'

'Contact to be just for me and mum, if other people are there mum will tell them to come back later.'

Dad added an extra one: 'If I am worried that anything is wrong at mum's then mum will let me have a look around the house before Matilda comes. If dad can not do this Matilda won't go.'

Once the plan was implemented, Matilda stopped going missing and her relationship with both parents improved.

In another example, three children devised a safety plan for being with their mother who was an alcoholic. Having listed what their mother needed to do to make them feel safe, they decided that she could not realistically achieve them and so they could not safely return home.

Bringing the child's views into planning meetings was found to have a significant impact on parents. In general, parents report that hearing and seeing their child's view about the effect of the parent's behaviour on them is a far more powerful motivator to change than being advised by a professional.

The Signs of Safety methods for planning safety provide specific means where children can not only contribute to the creation of the safety plan they can also take active roles in keeping themselves safe and communicate to adults that will make sure their concerns are dealt with. For example:

1. A child can have a 'safety object' and place it on the desk at school so that the teacher knows help is needed; 
2. Specific people are identified within the naturally connected support network and given the specific job of being the child's safety person. He or she will spend time alone with the child regularly checking with them that everything is okay;

3. Specific people are identified within the safety network that the child can call (usually using a one-touch facility on a mobile phone) who will come immediately (even in the middle of the night) and sort out the child's worries.

For more detailed information about involving children in child protection safety planning using the Signs of Safety approach see (Turnell and Essex 2013).

\subsection{Keeping Informed of What Is Happening and Why}

An English judge, Lady Butler-Sloss, made a pertinent comment in a major review of child protection practice: 'a child is a person and not an object of concern' (Department of Health and HMSO 1988). Sadly, there is evidence that many children are treated more as 'objects of concern' than as people when it comes to keeping them informed of what is happening to them and why (Munro 2011, p. 42). A series of focus groups with 140 children reported that it was clear that looked after children were often denied key information, especially about their background' (Wood and Selwyn 2017, p. 29). Child psychiatrist Tilman Furniss (2013) observed that 'child abuse is a syndrome of secrecy'. All families tend to create dynamics where difficult issues are avoided to keep the peace and because it is very difficult to find words to talk about embarrassing issues. When the issues involve situations where children could be or are hurt, it is even harder to speak about and children very often don't know why the problems have happened and often start to blame themselves. As Alcoholics Anonymous members assert, 'You're only as sick as your secrets'.

While it is easy for professionals to pathologize families for not talking openly about their problems, professionals themselves find it very 
difficult to speak to children about maltreatment they have experienced. This can affect children's general development through causing anxiety and distress and their ability to exercise their right to contribute to decision-making. Signs of Safety places strong emphasis on providing explanations to children through doing 'Words and Pictures'—asking the parent(s) to write a story explaining events in language and pictures that the child can understand. This can be done even if the child is very young because it can be kept until such time as they are old enough. If abuse is a syndrome of secrecy, it follows that openness is the foundation of safety and healing. For the child, this means they have an absolute right to an explanation from their parents and their family about abuse they have suffered and the problems that has caused that harm. Moreover, to minimize the distress and trauma children experience when professionals remove them from their parents, children need this explanation at the time of removal.

The following brief excerpt is the work of child protection practitioner Pene Turnell and colleagues in Western Australia. This example was created with the parents 'Teresa' and 'Marcus' and presented to their five-year-old son 'Marcus' within 48 hours of the removal. The parents, extended family and support people are always present when the story is read to the child.

'A Words and Pictures story so Sammy knows why he is staying with the foster family and why he can't live with Mummy Teresa and Daddy Marcus right now':

'On Saturday the Police called child protection workers because Daddy Marcus was at the BP petrol station acting and talking in a very strange way, like he didn't know where he was or what he was doing. The Police were worried because they were told Daddy had been driving in a dangerous way and they were worried that Sammy could get scared and hurt. Police thought Daddy Marcus was using drugs. Daddy Marcus says he doesn't remember but that he was very tired (Picture 5.2). 


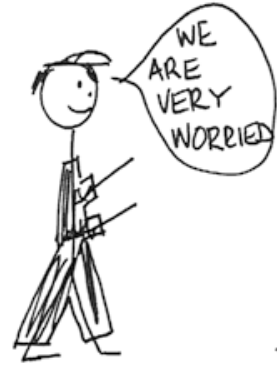

POLICE MAN

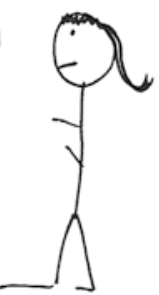

NATASHA SeClal worker

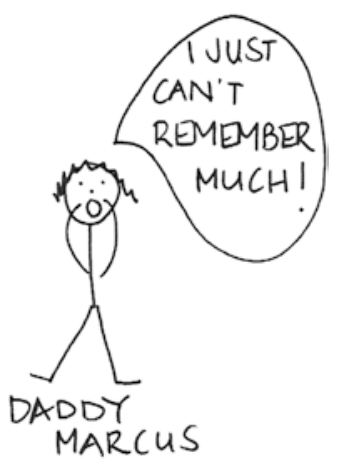

Picture 5.2 A words and pictures story

Later on Saturday, more people were worried about Sammy because he was in the MacDonald's car park and no adults were watching him. Police say Mummy Teresa was in the toilet and they think she was using drugs. Mummy Teresa said the Police were wrong and that balloon man was watching Sammy while she went to the toilet and got an ice cream for Sammy (Picture 5.3).
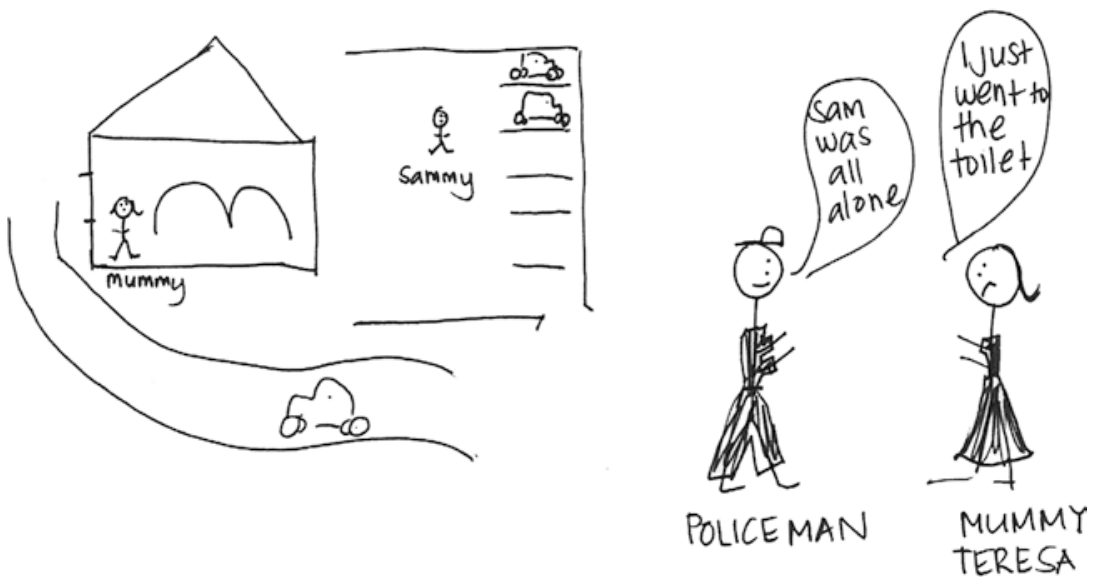

Picture 5.3 A words and pictures story 
Police told child protection workers about the problems and the workers were really worried so they went to the house. The workers told Mummy Teresa and Daddy Marcus that because of the worries Sammy would need to stay somewhere else while they talked with mum and dad about the problems. Mum Teresa helped workers by telling Sammy it was okay to go (Picture 5.4).
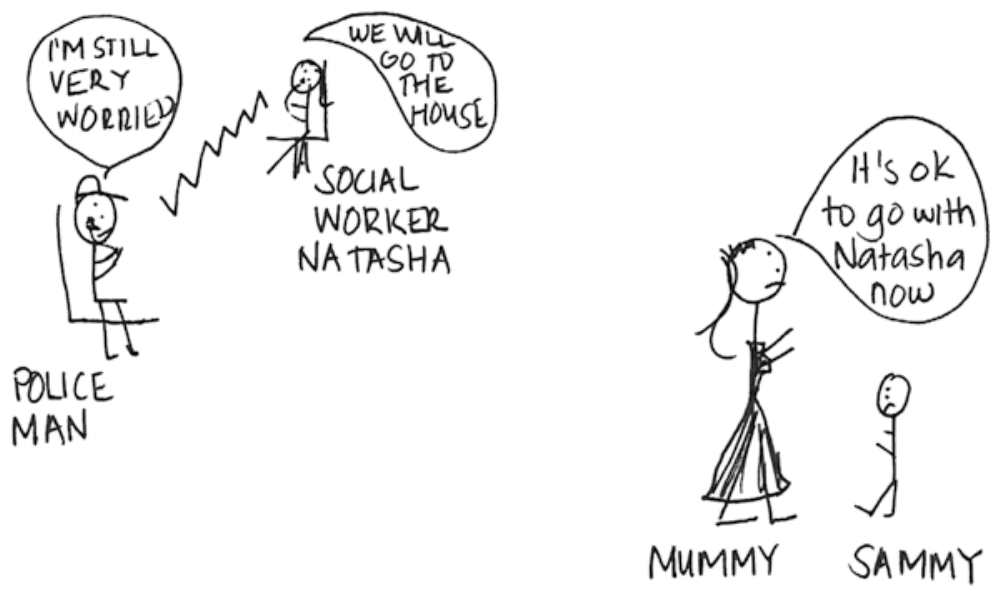

Picture 5.4 A words and pictures story

When they were in the car the workers asked Sammy about living with mum and dad. Sammy said that he likes it when mum and dad hug him but that he is scared when they cook glass and eat it and lose their minds. This made the workers more worried that mum and dad are using drugs even though they say they are not (Picture 5.5). 


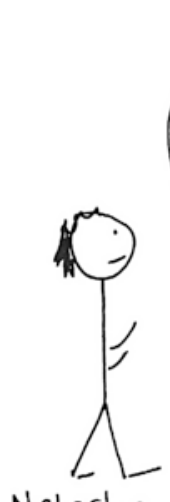

Natasha

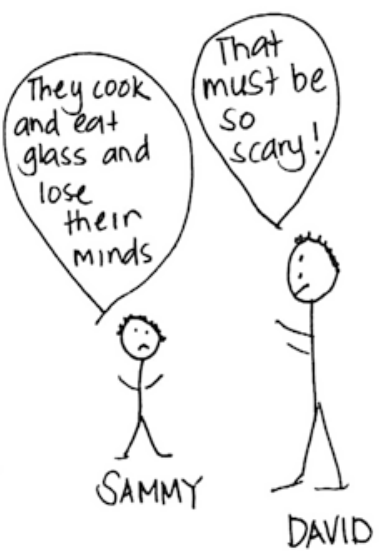

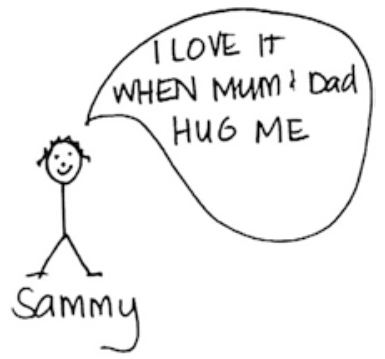

Picture 5.5 A words and pictures story

To talk about the worries, Mummy Teresa and her friend Brad came to a meeting with Patricia and Natasha and Natasha also spoke with Daddy Marcus on the phone. Mummy Teresa told Patricia that dad hits her a lot and that Sammy gets hit hard by Daddy Marcus too. Sammy told Darryl the social worker that dad had hit him across the face. Mummy Teresa said she knows that the hitting dad does and all the yelling at each other makes Sammy very scared (Picture 5.6). 
106

E. Munro and A. Tunnel


Picture 5.6 A words and pictures story

Because the police and child protection workers are worried that Sammy is scared and could get hurt by the drugs, the hitting, the dangerours driving and being left on his own they will talk to a Judge about what should happen. The workers will ask the Judge for permission for Sammy to live with the foster family while Mummy Teresa and Daddy Marcus work with them to make plans to solve the problems (Picture 5.7).
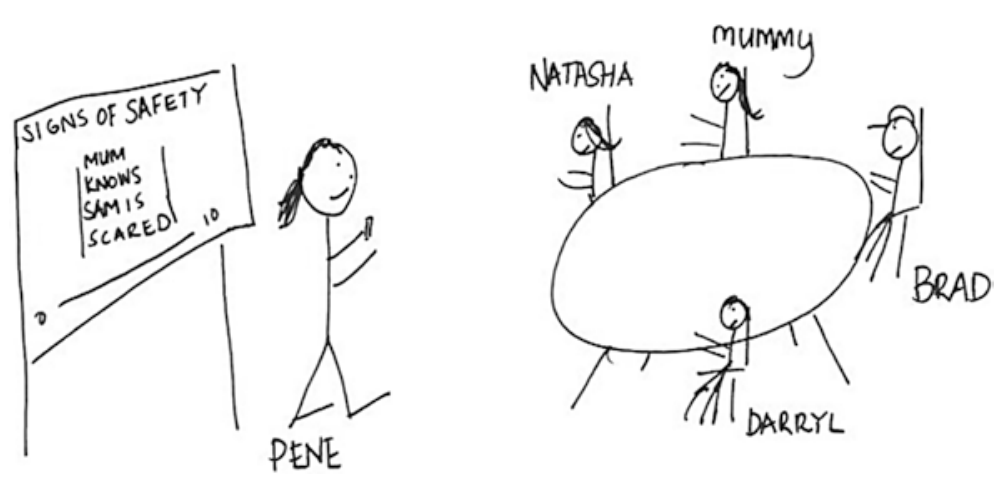

Picture 5.7 A words and pictures story 
While the meetings happen and plans are made, Sammy will live with the foster family who are caring for him. Mummy Teresa and Daddy Marcus love Sammy very much and the workers will make sure Sammy gets to see his mum and dad so he can play with them and tell them about what he has been doing.'

Creating an organizational appreciation of the importance of keeping children informed when they are removed from home was a major task that is not fully achieved yet. When removing a child, the worker has numerous legal and administrative documents to complete so that adding to the burden is a significant resource demand. However, time is always linked to priorities and the more that managers make it clear that they expect to see evidence of the child being informed, the higher it goes on the worker's list of priorities. Examples of completed 'Words and Pictures' help to convince people of how valuable they are.

\section{Conclusion: How the Convention Can Guide Professional Practice}

The experience of reforming child protection services to make them more focused on children as rights holders has highlighted the need for a whole-system approach. Signs of Safety is one practice framework that respects children's rights and contains a number of methods and tools to help the workforce treat children respectfully. On its own, however, it faces constant pressure from other organizational factors that make it hard for workers to keep a clear focus on children. The reforms required considerable alteration to organizational processes and documentation but the more important and harder change was in the culture: about what was important, how your work should be judged, and how the organization could support high-quality work with children and their families where workers were confident to exercise discretion, making judgments about what was best for this unique child instead of squeezing 
the child into a fixed set of categories and rules. One crucial change is in the way that practice is audited or quality assured. What gets measured, gets done, and so the measurements need to be of the quality of practice and the organizational culture within which workers are seeking to realize children's rights.

To end on a positive note, when given the opportunity to break away from an over-proceduralized style of work, people at all levels of seniority were very enthusiastic. They were also courageous in stepping out of their comfort zone into more child-focused work. Creating a culture that respects the rights of children is relatively easy in terms of gaining cooperation from the workforce but challenging in terms of the range of organizational factors that need to be changed to make it happen.

\section{Notes}

1. Building on work done by Nikki Weld, New Zealand.

\section{References}

Ashby, W. R. (1991). Principles of the self-organizing system. In G. J. Klir (Ed.), Facets of systems science. Boston: Springer.

College of Policing. (2009). Risk. London: College of Policing.

Dekker, S. (2007). Just culture, balancing safety and accountability. Aldershot: Ashgate.

Department of Health (2001). Building a safer NHS for patients: Implementing an organisation with a memory. London.

Department of Health and HMSO (1988). Report of the inquiry into child abuse in Cleveland, 1987. London.

Elsley, S. (2010). Media coverage of child deaths in the UK: The impact of baby P: $A$ case for influence. Edinburgh: University of Edinburgh/NSPCC Child Protection Research Centre.

Featherstone, B., Morris, K., \& White, S. (2013). A marriage made in hell: Early intervention meets child protection. British Journal of Social Work, 44, 1735-1749. 
Ferguson, H. (2017). How children become invisible in child protection work: Findings from research into day-to-day social work practice. The British Journal of Social Work, 47(4), 1007-1023.

Fischhoff, B. (1975). Hindsight-foresight: The effect of outcome knowledge on judgment under uncertainty. Journal of Experimental Psychology: Human Perception and Performance, 1(3), 288-299.

Furniss, T. (2013). The multiprofessional handbook of child sexual abuse: Integrated management, therapy, and legal intervention. London: Routledge.

Gilbert, N., Parton, N., \& Skiveness, M. (2011). Child protection systems: International trends and orientations. Oxford: Oxford University Press.

Kahneman, D. (2011). Thinking fast and slow. London: Allen Lane, the Penguin Press.

Lansdown, G. (2000). Implementing children's rights and health. Archives of Disease in Childhood, 83(4), 286-288.

Morgan, R. (2007). Children and safeguarding. London: Rights4me.

Munro, E. (2011). Munro review of child protection, final report: A child-centred system. London: Department for Education.

Munro, E., Turnell, A. \& Murphy, T. (2016). You can't grow roses in concrete (Action research final report). Perth: Resolutions Consultancy.

O'Donoghue, K., \& Tsui, M.-s. (2013). Social work supervision research (1970-2010): The way we were and the way ahead. The British Journal of Social Work, 45(2), 616-633.

Parton, N. (2009). Challenges to practice and knowledge in child welfare social work: From the 'social' to the 'informational'. Children and Youth Services Review, 31, 715-721.

Pösö, T. (2018). Experts by experience infusing professional practices in child protection. In A. Falch-Eriksen \& E. Backe-Hansen (Eds.), Human rights in child protection. Implications for professional practice and policy. London: Palgrave Macmillan.

Research in Practice. (2015). Voice of the child: Evidence review. London: Research in Practice.

Rushton, A., \& Nathan, J. (1996). The supervision of child protection work. British Journal of Social Work, 26, 357-374.

Sandberg, K. (2018). Children's right to protection under the CRC. In A. Falch-Eriksen \& E. Backe-Hansen (Eds.), Human rights in child protection. Implications for professional practice and policy. London: Palgrave Macmillan. 
Skivenes, M., \& Sørsdal, L. M. (2018). The child's best interest principle across child protection jurisdictions. In A. Falch-Eriksen \& E. Backe-Hansen (Eds.), Human rights in child protection. Implications for professional practice and policy. London: Palgrave Macmillan.

Thoburn, J. (2017). Children in state care. London: Routledge.

Thomas, N. (2015). The voice of the child in statutory work. In M. Ivory (Ed.), Voice of the child. London: Research in Practice.

Turnell, A. (2012). The signs of safety (Comprehensive briefing paper). Resolutions Consultancy.

Turnell, A., \& Essex, S. (2013). It takes a village. In Broad, B., Young, S., Operario, D., Turnell, A., Gleeson, J., Cluver, L., Flegg, E., Wyke, J., Crehan, G., Kuo, C. and Gough, A., 2013. Inside kinship care: Understanding family dynamics and providing effective support. Jessica Kingsley Publishers.

Unicef. (2011). General comment no. 13. New York: United Nations.

White, S., Wastell, D., Broadhurst, K., \& Hall, C. (2010). When policy o'erleaps itself: The 'tragic tale' of the integrated children's system. Critical Social Policy, 30(3), 405-429.

Wood, M., \& Selwyn, J. (2017). Looked after children and young people's views on what matters to their subjective well-being. Adoption and Fostering, 41(1), 20-34.

Open Access This chapter is licensed under the terms of the Creative Commons Attribution 4.0 International License (http://creativecommons.org/licenses/ by/4.0/), which permits use, sharing, adaptation, distribution and reproduction in any medium or format, as long as you give appropriate credit to the original author(s) and the source, provide a link to the Creative Commons license and indicate if changes were made.

The images or other third party material in this chapter are included in the chapter's Creative Commons license, unless indicated otherwise in a credit line to the material. If material is not included in the chapter's Creative Commons license and your intended use is not permitted by statutory regulation or exceeds the permitted use, you will need to obtain permission directly from the copyright holder.

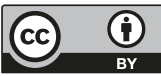

